\title{
Health Information Exchange in Emergency Medical Services
}

\author{
Thomas J. Martin ${ }^{1,2}$ Megan L. Ranney ${ }^{1,3}$ James Dorroh ${ }^{2}$ Nicholas Asselin ${ }^{1,3}$ Indra Neil Sarkar ${ }^{1,4}$
}

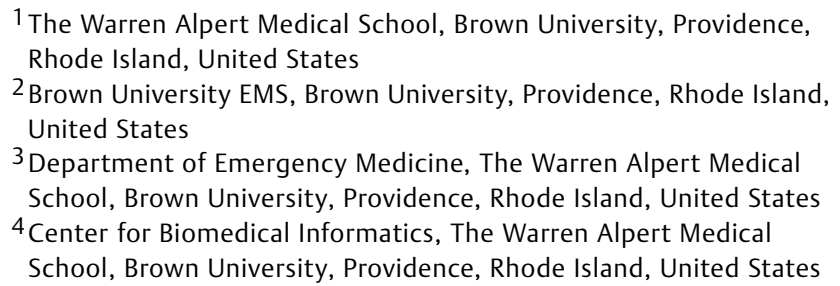

Address for correspondence Thomas J. Martin, BA, NRP, The Warren Alpert Medical School, Brown University, Box G-9487, Providence, RI 02912, United States (e-mail: thomas_martin@brown.edu).

Appl Clin Inform 2018;9:884-891.

\author{
Abstract \\ Keywords \\ - emergency medical \\ services \\ - emergency medical \\ service \\ communication \\ systems \\ - health information \\ exchange
}

Background The Office of the National Coordinator for Health Information Technology has outlined the benefits of health information exchange in emergency medical services (EMSs) according to the SAFR model-search, alert, file, and reconcile-developed in collaboration with the California Emergency Medical Services Authority.

Objective This scoping review aims to identify and characterize progress toward the adoption of prehospital health information exchange, as reported in the peer-reviewed literature.

Methods A structured review of literature in MEDLINE-indexed journals was conducted using the "Electronic Health Records" topic-specific query, the "Emergency Medical Services" Medical Subject Headings descriptor, and a prehospital identifier. Results Our initial search yielded 368 nonduplicative, English-language articles; 131 articles underwent full-text review and 11 were selected for analysis according to preestablished inclusion criteria. Original research was thematically grouped according to the SAFR model.

Conclusion Within isolated systems, there has been limited progress toward the adoption of prehospital health information exchange. Interoperability, accurate match algorithms, security, and wireless connectivity have been identified as potential barriers to adoption. Additional research is required to evaluate the role of health information exchange within EMSs.

\section{Background and Significance}

The National Highway Traffic Safety Administration has highlighted emergency medical services (EMSs) as an integral part of the health care delivery system. ${ }^{1}$ However, a 2006 Institute of Medicine report, Emergency Medical Services At the Crossroads, notes that although "EMS operates at the intersection of health care, public health, and public safety...local EMS systems are [often] not well integrated with any of these groups."

\section{received}

August 28, 2018

accepted after revision

October 16, 2018

The EMS-emergency department (ED) interface is a particularly important moment for integration due to the high-risk nature of patient handoffs for contributing to medical error. ${ }^{3}$ For many patients presenting to the ED via ambulance, prehospital providers may be the only available source of clinical information. Prehospital care reports document critical information for use by downstream providers that may impact clinical care or triage decisions. Failure to convey essential information during clinical handoffs can lead to critical gaps in (C) 2018 Georg Thieme Verlag KG
Stuttgart · New York
DOI https://doi.org/

10.1055/s-0038-1676041. ISSN 1869-0327. 
clinical knowledge, including home medications, field treatment, as well as other relevant findings identified during the initial patient encounter (e.g., social and behavioral factors). Without successful communication during patient handoff, this information may become altered, lost, or otherwise unavailable to emergency physicians or advanced practice providers at the time of or prior to medical decision making.

Though effective communication at the EMS-ED interface contributes to the provision of high-quality continuous care, recent quantitative analysis of clinical handoffs from prehospital providers to ED staff demonstrates that communication at this transfer of care remains suboptimal in critically ill or injured patients. ${ }^{4}$ Focus groups conducted with EMS providers have suggested that information technology may help close knowledge gaps during handover, yet also highlight the inconsistency with which information technology and prehospital medical records are utilized for this purpose. ${ }^{3}$

Despite the widespread adoption of health information technology by health care systems throughout the world, many EMS systems lack the infrastructure necessary to comprehensively manage or communicate prehospital data with other health care providers. ${ }^{5}$ Health information exchanges (HIEs) and regional health information organizations (RHIOs) are increasingly used by hospitals and outpatient providers to bridge information gaps and preserve continuity of care through exchange of laboratory results, radiology reports, clinical care summaries, and medication histories. ${ }^{6}$ Though longitudinal patient data may be queried and pulled by entities involved in HIE, the incorporation of EMS systems and inclusion of prehospital data within these networks remains largely unreported.

In 2016, The Office of the National Coordinator for Health Information Technology (ONC) released guidelines outlining the benefits of a real-time interface between HIEs and EMS. ${ }^{7}$ Through their collaboration with the California Emergency Medical Services Authority (EMSA) in the construction of the Patient Unified Lookup System for Emergencies (PULSE) and +EMS:SAFR (search, alert, file, and reconcile) systems, four ideal functionalities of EMS-HIE integration, summarized through the SAFR model, were described ${ }^{7,8}$ :

- Search an individual's electronic health record (EHR) for medical history, current medications, allergies, and endof life decisions.

- Alert receiving facilities with incoming patient information prior to ambulance arrival.

- File prehospital data from EMS electronic patient care report directly within hospital information system and HIE to create longitudinal records of care that document the disease course.

- Reconcile data such as diagnosis and disposition from the EHR within the prehospital record. ${ }^{7-9}$
The availability of electronic prehospital information linked to hospital information (e.g., diagnosis and disposition) is critical not only for the provision of high-quality, continuous care to individual patients, but also for systemslevel analyses. For example, EMS-HIE linkages may be used to enhance EMS quality improvement efforts, the development of evidence-based prehospital emergency care protocols, and the conduct of outcomes-based EMS research. It may also be useful for disaster management and novel care coordination initiatives such as mobile integrated health/ community paramedicine. ${ }^{10}$ EMS systems participating in HIEs have the potential to revolutionize the delivery of safe and efficient prehospital care through the development of integrated emergency care networks.

\section{Objective}

This scoping review seeks to identify progress toward integrating prehospital information systems within the larger health care community according to the SAFR model through evaluating the results of prior implementations as reported within the international peer-reviewed literature.

\section{Methods}

In August 2018, a search of peer-reviewed literature was conducted in MEDLINE using the PubMed "Electronic Health Records" topic-specific query, the "Emergency Medical Services" Medical Subject Headings descriptor, and a prehospital identifier as developed with a health science librarian ( - Table 1 ). Initial search results were organized using Abstrackr, a Web application designed to facilitate the citation-screening process by creating a workflow that allows multiple reviewers to simultaneously screen imported citations. ${ }^{11}$ Publications were screened for fulltext review and subsequently selected based on the following inclusion criteria: (1) written in English; (2) original research published in a MEDLINE-indexed peer-reviewed scholarly journal; and (3) presents results from the implementation of information technology to support prehospital HIE through at least one modality described by the SAFR model. Where disagreement existed between two independent authors regarding inclusion criteria, the senior author provided moderation. Due to wide variation in reported measures, study design, and objectives, it was not possible to identify a primary outcome or create a standardized process for data abstraction. Rather, data describing systems-level responses to the adoption of prehospital HIE were qualitatively abstracted and thematically grouped according to the SAFR model described by the ONC.

Table 1 Search terms and strategies

\begin{tabular}{|l|l|l|}
\hline Electronic Health Record & Emergency Services & Prehospital Identifier \\
\hline $\begin{array}{l}\text { PubMed “Electronic Health Records” } \\
\text { topic-specific query }\end{array}$ & $\begin{array}{l}\text { "Emergency Medical Services” } \\
{[\mathrm{MeSH}]}\end{array}$ & $\begin{array}{l}\text { Ambulance[tw], Emergency medical services[tw], } \\
\text { EMS[tw], Emergency medical technician[tw], } \\
\text { EMT[tw], Paramedic[tw], Prehospital[tw] }\end{array}$ \\
\hline
\end{tabular}




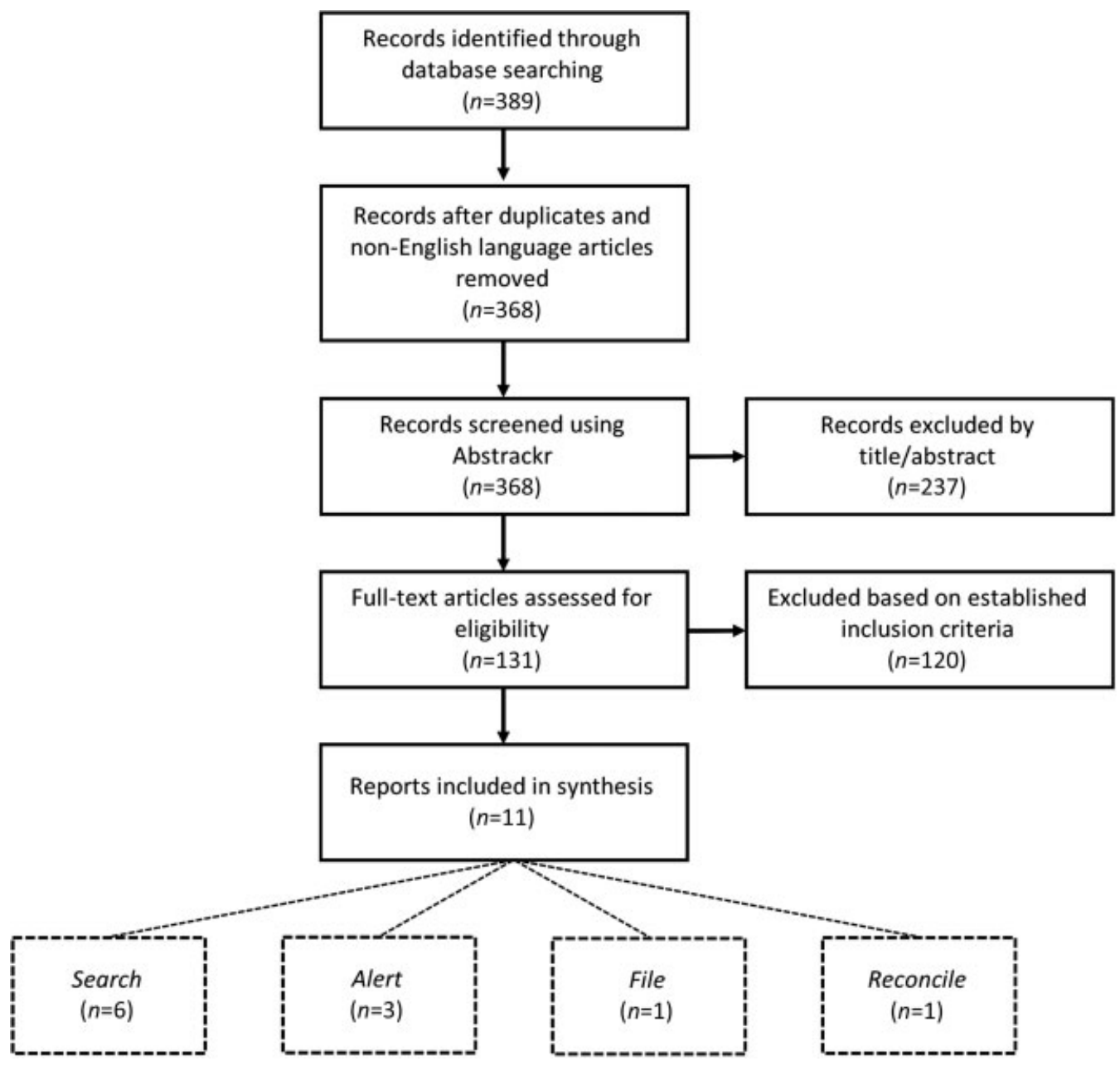

Fig. 1 Search results.

\section{Results}

The initial search yielded 368 nonduplicative, English-language articles. After an initial screening of abstracts, 131 articles were selected for full-text review, of which 11 were found to meet the aforementioned inclusion criteria ( - Fig. 1); the selected articles were then summarized and thematically grouped according to the SAFR model (- Table 2).

\section{Search}

Review of the literature yielded six publications with direct relevance to Search functionality. In 2003, the central Hampshire

Table 2 Summary of Included reports

\begin{tabular}{|c|c|c|c|c|c|c|}
\hline $\begin{array}{l}\text { Authors } \\
\text { (date) }\end{array}$ & Title & Setting & $\begin{array}{l}\text { SAFR } \\
\text { modality }\end{array}$ & Description & EMS-HIE integration & Relevant findings \\
\hline $\begin{array}{l}\text { Sanderson } \\
\text { et al (2004) }\end{array}$ & $\begin{array}{l}\text { Lessons from the } \\
\text { central Hampshire } \\
\text { electronic health record } \\
\text { pilot project: evaluation } \\
\text { of the electronic health } \\
\text { record for supporting } \\
\text { patient care } \\
\text { and secondary analysis }\end{array}$ & $\begin{array}{l}\text { England, } \\
\text { United Kingdom }\end{array}$ & Search & $\begin{array}{l}\text { Assess clinical utility } \\
\text { of central Hampshire } \\
\text { electronic health } \\
\text { record (CHEHR) in } \\
\text { supporting } \\
\text { unscheduled care }\end{array}$ & $\begin{array}{l}\text { EMS personnel can } \\
\text { access CHEHR for } \\
\text { patient information }\end{array}$ & $\begin{array}{l}\text { Poor reliability for } \\
\text { electronic health } \\
\text { record availability and } \\
\text { information } \\
\text { completeness due to } \\
\text { low levels of } \\
\text { participation in } \\
\text { CHEHR }\end{array}$ \\
\hline $\begin{array}{l}\text { Morris et al } \\
(2012)\end{array}$ & $\begin{array}{l}\text { The Scottish } \\
\text { Emergency Care } \\
\text { Summary-an evalua- } \\
\text { tion of a national } \\
\text { shared record system } \\
\text { aiming to improve } \\
\text { patient care: } \\
\text { technology report }\end{array}$ & $\begin{array}{l}\text { Scotland, } \\
\text { United Kingdom }\end{array}$ & Search & $\begin{array}{l}\text { Evaluate usefulness of } \\
\text { the Scottish } \\
\text { Emergency Care } \\
\text { Summary (ECS) in } \\
\text { supporting } \\
\text { unscheduled care }\end{array}$ & $\begin{array}{l}\text { EMS personnel can } \\
\text { access ECS for patient } \\
\text { information }\end{array}$ & $\begin{array}{l}\text { High levels of patient } \\
\text { participation in ECS, } \\
\text { provider usage of } \\
\text { system, and provider } \\
\text { assessment of } \\
\text { usefulness of patient } \\
\text { information available }\end{array}$ \\
\hline
\end{tabular}


Table 2 (Continued)

\begin{tabular}{|c|c|c|c|c|c|c|}
\hline $\begin{array}{l}\text { Authors } \\
\text { (date) }\end{array}$ & Title & Setting & $\begin{array}{l}\text { SAFR } \\
\text { modality }\end{array}$ & Description & EMS-HIE integration & Relevant findings \\
\hline $\begin{array}{l}\text { Craig et al } \\
(2015)\end{array}$ & $\begin{array}{l}\text { An evaluation of the } \\
\text { impact of the key } \\
\text { information summary } \\
\text { on GPs and out-of- } \\
\text { hours clinicians in NHS } \\
\text { Scotland }\end{array}$ & $\begin{array}{l}\text { Scotland, } \\
\text { United Kingdom }\end{array}$ & Search & $\begin{array}{l}\text { Identify health care } \\
\text { services impact of key } \\
\text { information summary } \\
\text { shared electronic } \\
\text { patient records }\end{array}$ & $\begin{array}{l}\text { EMS personnel can } \\
\text { access key informa- } \\
\text { tion summary records }\end{array}$ & $\begin{array}{l}\text { Providers welcome } \\
\text { access to patient } \\
\text { records through key } \\
\text { information summary, } \\
\text { which enhances } \\
\text { patient safety and aids } \\
\text { in clinical } \\
\text { management }\end{array}$ \\
\hline $\begin{array}{l}\text { Jones et al } \\
\text { (2009) }\end{array}$ & $\begin{array}{l}\text { An economic analysis } \\
\text { of the national shared } \\
\text { emergency care sum- } \\
\text { mary in Scotland }\end{array}$ & $\begin{array}{l}\text { Scotland, } \\
\text { United Kingdom }\end{array}$ & Search & $\begin{array}{l}\text { Analyze economic } \\
\text { sustainability of Scot- } \\
\text { tish ECS }\end{array}$ & $\begin{array}{l}\text { EMS personnel can } \\
\text { access ECS for patient } \\
\text { information }\end{array}$ & $\begin{array}{l}\text { After approximately } \\
7 \text { years, annual bene- } \\
\text { fits (nonfinancial and } \\
\text { redeployed finance) of } \\
\text { ECS implementation } \\
\text { exceed annual costs }\end{array}$ \\
\hline $\begin{array}{l}\text { Park and } \\
\text { Finnell (2012) }\end{array}$ & $\begin{array}{l}\text { Indianapolis emer- } \\
\text { gency medical service } \\
\text { and the Indiana Net- } \\
\text { work for Patient Care: } \\
\text { evaluating the patient } \\
\text { match algorithm }\end{array}$ & $\begin{array}{l}\text { Indiana, } \\
\text { United States }\end{array}$ & Search & $\begin{array}{l}\text { Evaluate effectiveness } \\
\text { of matching process } \\
\text { for EMS patient data } \\
\text { requests and electro- } \\
\text { nic records from Indi- } \\
\text { ana Network for } \\
\text { Patient Care (INPC) }\end{array}$ & $\begin{array}{l}\text { EMS personnel can } \\
\text { access patient elec- } \\
\text { tronic medical records } \\
\text { from INPC }\end{array}$ & $\begin{array}{l}73 \% \text { of authorized EMS } \\
\text { data requests resulted } \\
\text { in a unique patient } \\
\text { match; errors in zip } \\
\text { code identifiers } \\
\text { accounted for a } \\
\text { majority of failed } \\
\text { matches }\end{array}$ \\
\hline $\begin{array}{l}\text { Finnell and } \\
\text { Overhage } \\
(2010)\end{array}$ & $\begin{array}{l}\text { Emergency medical } \\
\text { services: the frontier } \\
\text { in health information } \\
\text { exchange }\end{array}$ & $\begin{array}{l}\text { Indiana, } \\
\text { United States }\end{array}$ & Search & $\begin{array}{l}\text { Evaluate EMS usage of } \\
\text { INPC system and pro- } \\
\text { vider satisfaction with } \\
\text { information delivered }\end{array}$ & $\begin{array}{l}\text { EMS personnel can } \\
\text { access patient elec- } \\
\text { tronic medical records } \\
\text { from INPC }\end{array}$ & $\begin{array}{l}\text { EMS usage of INPC } \\
\text { system increased dur- } \\
\text { ing study period; large } \\
\text { majority of providers } \\
\text { felt INPC patient } \\
\text { information was } \\
\text { important for quality } \\
\text { care }\end{array}$ \\
\hline $\begin{array}{l}\text { Anantharaman } \\
\text { and Swee Han } \\
(2001)\end{array}$ & $\begin{array}{l}\text { Hospital and emer- } \\
\text { gency ambulance link: } \\
\text { using IT to enhance } \\
\text { emergency prehospi- } \\
\text { tal care }\end{array}$ & Singapore & Alert & $\begin{array}{l}\text { Evaluate implementa- } \\
\text { tion of Hospital and } \\
\text { Emergency Ambu- } \\
\text { lance Link (HEAL) sys- } \\
\text { tem for transmitting } \\
\text { patient clinical data } \\
\text { from field to hospital }\end{array}$ & $\begin{array}{l}\text { HEAL system trans- } \\
\text { mits prehospital vital } \\
\text { signs and electrocar- } \\
\text { diograms to EDs in real } \\
\text { time for early } \\
\text { notification }\end{array}$ & $\begin{array}{l}\text { HEAL implementation } \\
\text { reduced mean time } \\
\text { elapsed from arrival to } \\
\text { physician evaluation } \\
\text { for critical patients, } \\
\text { also shortened EMS } \\
\text { turnaround time at } \\
\text { hospital }\end{array}$ \\
\hline $\begin{array}{l}\text { Walderhaug } \\
\text { et al (2008) }\end{array}$ & $\begin{array}{l}\text { Evacuation support } \\
\text { system for improved } \\
\text { medical documenta- } \\
\text { tion and information } \\
\text { flow in the field }\end{array}$ & Norway & Alert & $\begin{array}{l}\text { Evaluate EvacSys com- } \\
\text { puterized information } \\
\text { system for capturing } \\
\text { and sharing prehospi- } \\
\text { tal data in austere } \\
\text { environments }\end{array}$ & $\begin{array}{l}\text { Field medical and } \\
\text { tracking information is } \\
\text { transmitted to receiv- } \\
\text { ing facility for early } \\
\text { notification }\end{array}$ & $\begin{array}{l}\text { Surveyed medics } \\
\text { found EvacSys to be } \\
\text { more viable than } \\
\text { paper-based methods, } \\
\text { with no technical pro- } \\
\text { blems encountered; } \\
\text { early notification } \\
\text { allowed for better } \\
\text { treatment prepara- } \\
\text { tions prior to patient } \\
\text { arrival }\end{array}$ \\
\hline $\begin{array}{l}\text { Nakada et al } \\
(2016)\end{array}$ & $\begin{array}{l}\text { Development of a } \\
\text { prehospital vital signs } \\
\text { chart sharing system }\end{array}$ & Japan & Alert & $\begin{array}{l}\text { Determine effective- } \\
\text { ness of prehospital } \\
\text { vital signs chart shar- } \\
\text { ing system for relaying } \\
\text { patient vitals to } \\
\text { trauma center prior to } \\
\text { arrival }\end{array}$ & $\begin{array}{l}\text { Prehospital vital signs } \\
\text { are recorded and } \\
\text { transmitted in real } \\
\text { time to hospital for } \\
\text { early notification }\end{array}$ & $\begin{array}{l}\text { Prehospital vital signs } \\
\text { chart sharing system } \\
\text { increased the number } \\
\text { of prehospital patient } \\
\text { vital signs shared with } \\
\text { the trauma center } \\
\text { prior to arrival }\end{array}$ \\
\hline $\begin{array}{l}\text { Gaynor et al } \\
(2009)\end{array}$ & $\begin{array}{l}\text { A standardized pre- } \\
\text { hospital electronic } \\
\text { patient care system }\end{array}$ & $\begin{array}{l}\text { Massachusetts, } \\
\text { United States }\end{array}$ & File & $\begin{array}{l}\text { Evaluate iRevive } \\
\text { system for filing } \\
\text { prehospital care } \\
\text { information within } \\
\text { hospital records }\end{array}$ & $\begin{array}{l}\text { Interoperable, } \\
\text { forward compatible } \\
\text { prehospital electronic } \\
\text { medical record }\end{array}$ & $\begin{array}{l}77 \% \text { verified match } \\
\text { rate between prehos- } \\
\text { pital data and hospital } \\
\text { trauma registry }\end{array}$ \\
\hline $\begin{array}{l}\text { Nakae et al } \\
(2014)\end{array}$ & $\begin{array}{l}\text { Smartphone-assisted } \\
\text { prehospital medical } \\
\text { information system } \\
\text { for analyzing data on } \\
\text { prehospital stroke } \\
\text { care }\end{array}$ & Japan & Reconcile & $\begin{array}{l}\text { Evaluate smartphone- } \\
\text { assisted prehospital } \\
\text { medical information } \\
\text { system (SPMIS) for } \\
\text { facilitating prehospital } \\
\text { stroke care research }\end{array}$ & $\begin{array}{l}\text { EMS personnel can } \\
\text { access patient out- } \\
\text { comes and diagnoses } \\
\text { via SPMIS application }\end{array}$ & $\begin{array}{l}\text { SPMIS increased avail- } \\
\text { ability of prehospital } \\
\text { data linked to hospital } \\
\text { outcomes, enabling } \\
\text { evidence-based } \\
\text { research on EMS } \\
\text { stroke assessments }\end{array}$ \\
\hline
\end{tabular}

Abbreviations: ED, emergency department; EMS, emergency medical service; GP, general practitioner; HIE, health information exchange; IT, information technology; NHS, National Health Service; SAFR modality, search, alert, file, and reconcile modality. 
EHR (CHEHR) in the United Kingdom linked nearly 4.5 million discrete electronic patient records from sources including general practitioner offices, accident and emergency (A\&E) departments, National Health Service (NHS) Direct, social services, and various laboratories; CHEHR was piloted as a means to support emergency care delivered by out-of-hours clinicians, including NHS ambulance services, through providing access to previously unavailable records. ${ }^{12}$ Provider surveys from participating A\&E departments, general practitioners, and out-of-hours clinicians indicated that although desired clinical information was not universally available through CHEHR-presumably due to low rates of participation in the pilot project-available information was useful for supporting clinical decision making in the provision of emergency care. ${ }^{12}$

NHS Scotland piloted a similar system that was nationally launched in 2006. ${ }^{13}$ The Scottish Emergency Care Summary utilized an "opt out" model of consent to synchronize patient information (e.g., current medications and known drug allergies) from general practitioner information systems within a centralized database twice daily. ${ }^{13}$ This system was designed such that with direct consent, patient records could be consulted by out-of-hours clinicians, accident and emergency staff, or the Scottish ambulance service during unscheduled emergency care. ${ }^{13,14}$ The recently implemented "key information summary" provides clinicians with direct access to medical history, special notes, end-of-life decisions, and emergency contact information. ${ }^{14}$ Emergency Care Summary was shown to be economically sustainable ${ }^{15}$ and has become widely regarded as an integral resource for increasing patient safety during the delivery of unscheduled care within Scotland ${ }^{14}$; as of 2012, the database contained the records of $99.9 \%$ of the Scottish population, of which 50,000 are accessed per week. ${ }^{13}$

In 2009, the Indiana Network for Patient Care (INPC) was the first regional HIE in the United States to grant prehospital providers access to preexisting electronic records through real-time information exchange. ${ }^{16,17}$ The integration of EMS electronic records with the INPC allowed Indianapolis paramedics to initiate query-based exchanges with the local RHIO; search requests were formatted as messages according to the Health Level Seven International (HL7) standards containing patient demographics and prehospital provider authentication. ${ }^{17}$ Over the course of investigational periods in 2010 and 2012, paramedics requested data access during 16 and $14 \%$ of $9-1-1$ activations, respectively. ${ }^{16,17}$ of 1,916 requests for INPC data by authorized EMS providers over a 12-month period, $1,398(73 \%)$ resulted in a unique patient match. ${ }^{16}$ Following a successful match, the INPC returned an HL7 response message with the option to accept the patient's "EMS abstract," a snapshot summary of their electronic medical record in PDF format. ${ }^{17}$ Surveys of participating paramedics showed that the information contained in the EMS abstract was rated as important to very important in providing care by two-thirds of the respondents; furthermore, the majority of respondents indicated that the EMS abstract was of the most value in patients who were unable to adequately communicate their medical history, such as elderly patients with extensive comorbidities. ${ }^{17}$ Still, poor
Internet connectivity was the most frequently cited reason by Indianapolis paramedics for not requesting an EMS abstract from the INPC. ${ }^{17}$

\section{Alert}

This review identified multiple publications describing prototype systems in various stages of development, yet only three studies described systems that were implemented in the field to achieve Alert functionality. In 2001, the Hospital and Emergency Ambulance Link (HEAL) was created as a pilot system in Singapore to enable the real-time transmission of the entire prehospital case record-including vital signs and electrocardiogram waveform-from the field to a nearby ED. ${ }^{18}$ Early alerts provided via HEAL allowed hospitals to register patients and activate appropriate resources in anticipation of patient arrival, thereby reducing delays to definitive care. ${ }^{18}$ Under the HEAL system, the mean time from ED arrival to physician evaluation was 19 minutes for Priority 2 (i.e., moderately ill) patients whose data were transmitted prearrival $(n=635)$, compared with a mean time of 34 minutes for similar Priority 2 patients transported by non-HEAL ambulances $(n=384) .{ }^{18}$ Additionally, paramedics using HEAL returned to service an average of 9 minutes sooner compared with non-HEAL crews, thus decreasing turnaround delay in the ED and increasing the availability of limited prehospital resources. ${ }^{18}$

The second system, EvacSys, was developed and piloted in 2003 by military medical personnel from Norway and the United States for the capture and transmission of prehospital data in austere environments. ${ }^{19}$ EvacSys replaced conventional forms of paper documentation and transmission by voice communication with electronic information capture and sharing. ${ }^{19}$ Notably, structured interviews with participating medics indicated that the system's medical early warning feature allowed them to be better prepared for the immediate assessment and treatment of patients because critical information was already shared prior to patient arrival. ${ }^{19}$

A prehospital vital signs chart sharing system, recently developed in Japan and piloted at a Level I trauma center, was implemented in the civilian environment. ${ }^{20}$ This system used ambulance monitors to continuously obtain prehospital vital signs data, which were stored in a tablet computer and securely transmitted over a cellular phone to a cloud server that automatically generated an electronic prehospital chart for trauma center staff prior to patient arrival. ${ }^{20}$ Deployment of this system resulted in statistically significant increase $(p<0.0001)$ in the number of vital signs accurately shared with the trauma center, which greatly decreases the potential for information loss during clinical handover at the EMS-ED interface. ${ }^{20}$

\section{File}

One publication was identified that described the implementation of a system that best demonstrates the File functionality of the SAFR model. iRevive is an interoperable, forward compatible prehospital electronic medical record that was developed by 10Blade, Inc., the University of Arizona, and Boston MedFlight (BMF). ${ }^{21}$ iRevive uses wireless sensors in conjunction with manual data entry to store prehospital vital signs 
data on a timeline, thus creating an electronic prehospital patient case record. ${ }^{21}$ Uniquely, the iRevive application is designed as "a flexible superset of schemas, which can morph into any component schema." ${ }^{21}$ As such, to allow information exchange with a new hospital or EMS agency utilizing noncompatible standards, this "data mediator approach" only requires translation to and from the common data format of iRevive rather than between the standards of each entity with whom the information is exchanged. ${ }^{21}$ iRevive was field tested by exchanging historical BMF data with the Trauma Registry of the American College of Surgeons at Boston Medical Center (BMC). From a total of 373 patients transported by BMF, iRevive generated 286 verified matches (77\%), which the authors attributed to the fact that not all BMF transports are trauma cases, and therefore those patients should not exist in the registry. ${ }^{21}$ In addition to providing prehospital data to receiving facilities prior to patient arrival-satisfying the Alert functionality of SAFR-iRevive also "files" prehospital care information from BMF within hospital records at BMC to create one longitudinal record of care. ${ }^{21}$

\section{Reconcile}

We identified one publication describing a system that implemented the Reconcile function of SAFR. A group in Japan recently piloted a smartphone-assisted prehospital medical information system (SPMIS) application for use by emergency responders. ${ }^{22}$ SPMIS allowed EMS personnel to wirelessly transmit the prehospital data including demographics, clinical presentation (e.g., Cincinnati stroke scale), and tentative prehospital diagnosis associated with a specific transportation identification (ID) to the receiving ED prior to arrival. ${ }^{22}$ On arrival, ED staff assigned patients a hospital ID which was entered into the prehospital electronic record, enabling the subsequent reconciliation of in-hospital data (e.g., patient outcome, diagnosis 1 week postadmission) within the prehospital database for EMS personnel to access. $^{22}$ The SPMIS pilot thereby increased the availability of prehospital data linked to hospital outcomes for real-time analysis and evidence-based research, such as using the data to determine the predictive values of prehospital diagnosis and EMS use of the Cincinnati stroke scale. ${ }^{22}$

\section{Discussion}

In this review, we provide an overview of the state of research on prehospital HIE as reported in the peer-reviewed literature. Using the SAFR model developed by the California EMSA and the ONC as a guideline, ${ }^{7,8}$ we identified 11 publications describing the deployment of feasible systems to exchange information between EMS providers and other members of the health care system. These articles illustrate the feasibility and potential efficacy of such systems to realize the ONC's vision for EMS-HIE integration and improve patient-centered outcomes through the delivery of safe, efficient prehospital care.

As the role of EMS providers within the larger health care delivery system continues to expand, there is an increasing need for prehospital access to preexisting patient data. Prehospital access to pertinent information including current medications, allergies, past medical history, and end-of-life decisions may be limited by several factors. Integrating EMS with state-based HIEs or other RHIOs may mitigate these challenges by providing authorized EMS providers with the requisite information for the delivery of safer care. Integration may be especially beneficial during disaster response where access to patient information is often limited. Prearrival notifications through integrated systems may further improve resource allocation at receiving hospitals and provide opportunities to divert patients to alternative facilities if surge capacity is exceeded. Although some states and private entities have developed systems with limited SAFR functionality for this purpose, this review demonstrates that the overall adoption of this technology and the success of current systems for information exchange at the EMS-ED interface remains largely uncharacterized in the literature.

The absence of high-quality, published research in this area warrants consideration of what barriers continue to prevent efforts to bridge data silos and information gaps within emergency care networks. This review has identified broad concerns regarding interoperability, security, accurate patient match algorithms, and the reliability of wireless networks as potential barriers to adoption. Yet, the systems identified herein, as well as those under development in California, ${ }^{8,9}$ demonstrate how innovative solutions may be employed through the incorporation of EMS within the existing HIEs. Analogous efforts to improve HIE between U.S. poison control centers and EDs have successfully used user-centered design and changes in staff documentation practices to improve system usability and increase the accuracy of patient match algorithms, respectively. ${ }^{23,24}$ These strategies should also be considered to overcome the challenges associated with prehospital information exchange. The continued development of FirstNet-a high-speed, national broadband network to be exclusively utilized by first responders ${ }^{25}$-may also offer increasing opportunities to advance communication at the EMS-ED interface and further integrate EMS providers within the larger emergency care networks in which they operate.

The integration of EMS systems with the broader health care community will become increasingly necessary for addressing current information gaps, namely, those at the EMS-ED interface. Effective EMS-HIE integration may offer improvements at systemic and individual levels. Implementation of bidirectional information exchange according to the SAFR model presents opportunities for increased outcomesbased research and quality improvement in prehospital medicine, public health analyses of EMS utilization, and improved frameworks for real-time population health surveillance and disaster response. Future research is needed to ascertain the current availability and utility of prehospital data within the ED for clinical decision support, examine the effects of implementing systems such as California's PULSE and +EMS:SAFR on workflow and the delivery of prehospital care, and determine best practices for integrating EMS in individual systems throughout the world.

The scope of this review is limited by our search terms and our decision to only include MEDLINE-indexed peer-reviewed literature. It is likely that novel HIE implementations that 
include EMS systems may be proprietary or under development and thus remain to be described in the peer-reviewed medical literature (e.g., Pulsara, Twiage, iTriage, +EMS:SAFR). Without a survey of EMS agencies or HIEs, we are unable to infer actual rates of integration at local, state, national, or international levels. Furthermore, due to the absence of consistent outcomes measures for SAFR systems and the wide variation in study designs, we were unable to perform standardized data abstraction or synthesis. These points highlight the critical need for further research on the safety and efficacy of current modalities of information exchange utilized by EMS systems, as well as the long-term costs and benefits of implementing the SAFR functionality.

\section{Conclusion}

This structured review both illustrates the potential for HIE to improve communication and facilitate handoff at the EMS-ED interface, and highlights the need for well-designed research that demonstrates its effect on outcomes. Eleven articles were identified in the MEDLINE-indexed peerreviewed literature that demonstrate the feasibility of implementing new prehospital information systems to facilitate the bidirectional flow of clinical data from EMS providers in the field to clinicians in the ED. Timely access to patient information on both sides of the emergency care continuum may facilitate clinical handoff, preserve continuity of care, and decrease the risk of medical error. While progress toward limited SAFR functionality has been made in isolated systems, there remains a great need to advance integration efforts throughout the world. Future work should seek to implement fully functional prehospital-ED bidirectional information exchange that incorporates all four elements of the SAFR model, to establish the safety of these exchanges, and to examine their influence on outcomes.

\section{Clinical Relevance Statement}

Clinical handoff between emergency medical services and receiving staff in the emergency department is a critical moment within emergency care networks. Access to complete and accurate patient information is essential for optimal medical decision making in both the prehospital and inhospital settings. Integrating prehospital information systems within larger health information exchanges may improve continuity of care and decrease the risk of medical error.

\section{Multiple Choice Questions}

1. At its core, refers to the sharing of clinical information among different healthcare organizations.

a. Interoperability.

b. SAFR.

c. Health information exchange.

d. Data reconciliation.

Correct Answer: The correct answer is option c. Health information exchange refers to the sharing or transfer or clinical information between two or more entities (e.g., private physician, hospital, EMS). Thus, $\mathrm{c}$ is the correct answer.

2. In 2009, the Indiana Network for Patient Care (INPC) became the first regional health information exchange to provide local paramedics with access to patient records in the field. By initiating query-based exchanges with the INPC, these paramedics participated in which aspect of the SAFR model?
a. Search.
b. Alert.
c. File.
d. Reconcile.

Correct Answer: The correct answer is option a. The SAFR model proposed by the ONC outlines four ideal functionalities of EMS-HIE integration: Search, Alert, File, and Reconcile. Search refers to the ability of paramedics to search an individual's EHR for essential information including medical history, current medications, allergies, or end-of-life decisions. Thus, a is the correct answer.

3. When considering the SAFR model, which of the following scenarios best demonstrates the "Alert" functionality?

a. EMS notifies the public of impending natural disaster.

b. EMS queries the HIE in the prehospital setting.

c. EMS deposits prehospital care reports within the HIE.

d. EMS provides pre-arrival notification of suspected stroke to a receiving facility.

Correct Answer: The correct answer option d. The SAFR model proposed by the ONC outlines four ideal functionalities of EMS-HIE integration: Search, Alert, File, and Reconcile. Alert refers to the ability of EMS agencies to notify receiving hospitals of incoming patients prior to ambulance arrival. This is best illustrated by option $\mathrm{d}$ where prearrival notification of a suspected stroke by EMS may reduce delays associated with patient registration or stroke team activation.

4. A physician is called to the emergency department to evaluate a patient who was activated as a "Code Stroke" after arrival via ambulance, but is unable to assess when the patient's symptoms began. Based on reviewing data from the patient's prehospital care report that was automatically uploaded to the hospital's electronic health record, she is able to determine that the patient is a candidate for thrombolysis. Which element of SAFR, is illustrated by this scenario?
a. Search.
b. Alert.
c. File.
d. Reconcile.

Correct Answer: The correct answer is option c. Clinical handoff at the EMS-ED interface may result in the loss of key information delivered via verbal report. In this scenario, a physician was not able to complete her assessment of a patient presenting with stroke symptoms to the ED due to 
information loss during transfer of care. Because prehospital data were uploaded directly within the hospital's EHR, she was able to retrieve essential information for medical decision making. Thus, this scenario best illustrates option c "File" functionality included in the SAFR model.

\section{Protection of Human and Animal Subjects}

There were no human or animal subjects included in this review.

\section{Funding}

This work was funded in part by National Institutes of Health grant U54GM115677 and K23MH095866. The content is solely the responsibility of the authors and does not necessarily represent the official views of the National Institutes of Health.

\section{Conflict of Interest}

None declared.

\section{Acknowledgment}

The authors thank Erika Sevetson from the Brown University Library for her help in developing the search query.

\section{References}

1 Administration NHTS. Others. EMS Agenda for the Future. Washington, DC: National Highway Traffic Safety Administration; 1996

2 Institute of Medicine (U.S.). Emergency Medical Services at the Crossroads. Washington, DC: National Academies Press; 2007

3 Meisel ZF, Shea JA, Peacock NJ, et al. Optimizing the patient handoff between emergency medical services and the emergency department. Ann Emerg Med 2015;65(03):310-317

4 Goldberg SA, Porat A, Strother CG, et al. Quantitative analysis of the content of EMS handoff of critically ill and injured patients to the emergency department. Prehosp Emerg Care 2017;21(01):14-17

5 Landman AB, Rokos IC, Burns K, et al. An open, interoperable, and scalable prehospital information technology network architecture. Prehosp Emerg Care 2011;15(02):149-157

6 Swain M, Charles D, Patel V, Mpa TS. Health Information Exchange among U.S. Non -Federal Acute Care Hospitals: 2008-2014. The Office of the National Coordinator for Health Information Technology; 2015. Available at: https://www.healthit.gov/sites/default/files/databrief/ONC_DataBrief24_HIE_Final.pdf. Accessed October 31, 2018

7 Health Information Exchange \& Emergency Medical Services. Available at: https://www.healthit.gov/sites/default/files/HIE_Value_Prop_EMS_Memo_6_21_16_FINAL_generic.pdf. Accessed October 31, 2018

8 Smiley DR, Stratton SJ. Armed with History: Orange County, Calif., begins field implementation of EMS access to patient history via bidirectional information exchange. JEMS 2017;42(05):25-29
9 Minch D. The California EMS Projects. Presented at the NEMSIS TAC 2016 Annual Meeting; October 18, 2016; Lodges at Deer Valley, Park City, Utah. Available at: www.nemsis.org. Accessed October 31, 2018

10 Health Information Exchange Issue Brief: National Emergency Medical Services Use Cases. Available at: https://www.healthit. gov/sites/default/files/IssueBrief-NationalEMS_Use_Cases.pdf. Accessed October 31, 2018

11 Wallace BC, Small K, Brodley CE, Lau J, Trikalinos TA. Deploying an Interactive Machine Learning System in an Evidence-based Practice Center: Abstrackr. In: Proceedings of the 2Nd ACM SIGHIT International Health Informatics Symposium. IHI '12. New York, NY, USA: ACM; 2012:819-824

12 Sanderson H, Adams T, Budden M, Hoare C. Lessons from the central Hampshire electronic health record pilot project: evaluation of the electronic health record for supporting patient care and secondary analysis. BMJ 2004;328(7444):875-878

13 Morris LMM, Brown C, Williamson M, Wyatt JC. The Scottish Emergency Care Summary-an evaluation of a national shared record system aiming to improve patient care: technology report. Inform Prim Care 2012;20(01):41-49

14 Craig J, Morris L, Cameron J, et al. An evaluation of the impact of the key information summary on GPs and out-of-hours clinicians in NHS Scotland. Scott Med J 2015;60(03):126-131

15 Jones T, Dobrev A, Cameron J, Morris L, Stroetmann KA, Stroetmann VN. An economic analysis of the national shared Emergency Care Summary in Scotland. J Telemed Telecare 2009;15(03):129-131

16 Park SC, Finnell JT. Indianapolis emergency medical service and the Indiana Network for Patient Care: evaluating the patient match algorithm. AMIA Annu Symp Proc 2012;2012:1221-1228

17 Finnell JT, Overhage JM. Emergency medical services: the frontier in health information exchange. AMIA Annu Symp Proc 2010; 2010:222-226

18 Anantharaman V, Swee Han L. Hospital and emergency ambulance link: using IT to enhance emergency pre-hospital care. Int J Med Inform 2001;61(2-3):147-161

19 Walderhaug S, Meland PH, Mikalsen M, Sagen T, BrevikJI. Evacuation support system for improved medical documentation and information flow in the field. Int J Med Inform 2008;77(02):137-151

20 Nakada T-A, Masunaga N, Nakao S, et al. Development of a prehospital vital signs chart sharing system. Am J Emerg Med 2016;34(01):88-92

21 Gaynor M, Myung D, Gupta A, Moulton S. A standardised prehospital electronic patient care system. Int J Electron Healthc 2009;5(02):102-136

22 Nakae T, Kataoka H, Kuwata S, Iihara K. Smartphone-assisted prehospital medical information system for analyzing data on prehospital stroke care. Stroke 2014;45(05):1501-1504

23 Cummins MR, Ranade-Kharkar P, Johansen C, et al. Simple workflow changes enable effective patient identity matching in poison control. Appl Clin Inform 2018;9(03):553-557

24 Nelson SD, Del Fiol G, Hanseler H, Crouch BI, Cummins MR. Software prototyping: a case report of refining user requirements for a health information exchange dashboard. Appl Clin Inform 2016;7(01):22-32

25 First Responder Network Authority. FirstNet. Available at: http:// www.firstnet.gov. Accessed August 1, 2018 